\title{
The use of voice processing techniques in the assessment of patients with Parkinson's disease
}

Ewelina Majda-Zdancewicz, Andrzej Dobrowolski, Anna Potulska-Chromik, Jacek Jakubowski, Jolanta Chmielińska, et al.

Ewelina Majda-Zdancewicz, Andrzej Dobrowolski, Anna Potulska-Chromik, Jacek Jakubowski, Jolanta Chmielińska, Kamila Białek, Monika Nojszewska, Anna Kostera-Pruszczyk, "The use of voice processing techniques in the assessment of patients with Parkinson's disease," Proc. SPIE 11442,

Radioelectronic Systems Conference 2019, 114420H (11 February 2020); doi: $10.1117 / 12.2565132$ 


\title{
The use of voice processing techniques in the assessment of patients with Parkinson's disease
}

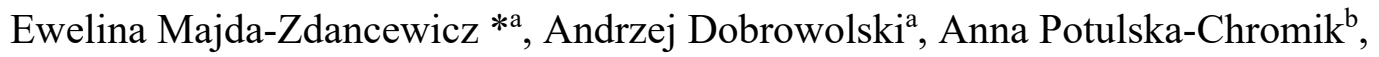 \\ Jacek Jakubowski ${ }^{\text {a }}$, Jolanta Chmielińska ${ }^{a}$,Kamila Białek ${ }^{\text {a }}$, \\ Monika Nojszewska ${ }^{b}$, Anna. Kostera-Pruszczyk ${ }^{b}$ \\ ${ }^{\text {a }}$ Military University of Technology, Faculty of Electronics, Gen. Sylwestra Kaliskiego Street No 2, \\ 00-908 Warsaw, Poland; ' Medical University of Warsaw, Department of Neurology, \\ Banacha Street No 1a, 02-097 Warsaw, Poland,
}

\begin{abstract}
Parkinson's disease (PD) is a neurodegenerative disease, which is becoming an increasingly greater social issue due to the growing incidence rate caused by population ageing. Over the recent years, the doctors have been focusing on searching for new methods supporting the diagnosis of such disorders. Acoustic voice analysis in Parkinson's patients can be a valuable and objective tool supporting the diagnosing diseases of neurodegenerative nature. The article discusses a concept of utilizing voice processing techniques in evaluating patients with Parkinson's disease. Using time analysis, frequency analysis and time-frequency analysis, the authors attempted performing acoustic voice analysis in that group of patients. The research utilized recordings conducted at the Department of Neurology at the Medical University of Warsaw. The study involved both women and men. The recording scenario was divided into several parts. The first part contained two various texts read out by the tested person. Yet another segment involved recording the vowel "a" with prolonged phonation, uttered by a patient for at least 5 seconds. The last part of the recordings involved the patient uttering individual words and sentences according to an assumed scenario. A total of 7 acoustic signals per patient, with an average length of ca. 75 seconds were recorded. The conclusions from the conducted studies will enable determining, which of the applied techniques can be a promising tool for supporting the diagnostics of neurodegenerative disorders, including parkinsonism. Further studies involving larger groups are required in order to confirm the obtained results and the structure of a target diagnostic system.
\end{abstract}

Keywords: acoustic analysis, Parkinson's disease, objective voice analysis

\section{INTRODUCTION}

PD - Parkinson's disease is one of the most common neurodegenerative diseases. PD is associated with neurodegeneration of the midbrain structure, i.e., black substance and leads to decreased dopamine levels in the brain. The etiopathogenesis of this disease is not fully known [1]. This is the second most occurring neurodegenerative disease, after Alzheimer's disease. Its significance grows along with the ageing of the population. It has a progressing nature. Initially (for as many as 5-10 years), preclinical symptoms are observed, which precede the occurrence of the most characteristic ones (tremor, slowness). Those appearing during this period may include worse balancing with one limb when walking, shoulder stiffness and pain, hitching with one leg when walking, sleeping disorders and constipation. However, the preclinical symptoms are so non-specific that they do not enable a diagnosis. The clearly clinical period involves classic motion-related symptoms of Parkinson's disease. There is no known method for slowing down the disease - it is of progressing nature. However, numerous drugs are known to alleviate its symptoms [2]. One of the most frequently used is L-DOPA, which is a precursor of dopamine. This preparation passes through the blood-brain barrier, and after converting into dopamine, it replenishes its deficiency in the brain. Its discovery (over 40 years ago) and application was a huge breakthrough in treating PD [1].

*ewelina.majda@wat.edu.pl; phone +48 26183 75 34; www.wel.wat.edu.pl

Radioelectronic Systems Conference 2019, edited by Piotr Kaniewski, Jan Matuszewski, Proc. of SPIE Vol. 11442, 114420H · @ 2020 SPIE · CCC code: 0277-786X/20/\$21 · doi: 10.1117/12.2565132 
In the course of Parkinson's disease, ca. 70 to $90 \%$ of the patients experience speech disorders. They appear already at an early stage and are of varying character [3, 4]. James Parkinson described speech disorders as one of the distinguishing symptoms of PD, however he also stated that they did not represent deteriorated intellectual capacities of the patient $[3,5]$. Most patients however do not notice their speech issues, while they are frequently the first symptom of the disease [3, 4]. A classic evaluation of speech disorders is most commonly conducted by a neurologist. Nonetheless, it is a subjective assessment carried out with the help of hearing only. In an ideal scenario, additional speech disorder evaluation could be conducted by an experienced phoniatrician, logopedist or speech therapist.

As a result, the value of such an examination strongly depends on the experience of a physician conducting it, as well as his/her ability to perceive acoustic phenomena.

Despite the constant development in research on the background of neurodegenerative diseases, no efficient treatment for such diseases has been found and there is no simple algorithm in terms of diagnosis and further procedures. The diagnostics of Parkinson's disease is primarily based on clinical criteria $[1,6,7]$. The survival time in patients with PD increases along with the development of treatment methods (pharmacological and neurosurgical) and varies depending on the age of patients.

\section{MATERIAL}

The objective of the tests conducted by the authors is an attempt at using voice processing techniques in evaluating patients with Parkinson's disease. The experiments presented within the studies are a part of a project on collecting multimodal data for the purposes of supporting and objectivization of the Parkinson's disease evaluation [8]. Such a stand includes an infrared camera, visible range camera [9], microphone with a preamplifier, a graphic tablet and a portable computer. Expanding this issue, the idea of the research concentrates on attempts to husk information "invisible to the naked eye". In relation to classic PD diagnostic methods, the acoustic analysis will enable objective and accurate assessment of several voice features, previously evaluated only subjectively using the hearing-based method, as well as detecting discrete speech impairment unnoticeable perceptually.

The research utilized recordings conducted at the Department of Neurology at the Medical University of Warsaw. The patients participating in the study were selected by their score in the so-called UPDRS The Unified Parkinson's disease Rating Scale). The UPDRS was published in 1987 and since then it has become a so-called gold standard for evaluating PD symptom intensification - higher results on this scale indicate a more advanced stage. This scale is validated once every several years and currently there are four parts of its assessment $[10,11]$ :

- $\quad$ Part I (Non-motor experiences of daily living),

- $\quad$ Part II (Motor experiences of daily living),

- $\quad$ Part III (Motor examination),

- $\quad$ Part IV (Motor complications).

UPDRS was used as the main indicator in selecting patients for the analysed experiments. The cases of patients in the low-scale UPDRS Parkinson's disease are particularly interesting. It should also be noted that the patients participating in the study were in the so-called "on" phase, meaning they were under the influence of medicines, which alleviated disease symptoms. As a result of such assumptions, the acoustic analysis of the patients' voice was hindered due to the applied treatment with L-DOPA drugs that effectively improved patient's condition.

The study involved both women and men. The material comprised of 8 patients (5 women and 3 men, aged 28-64, average: 52.3) with diagnosed Parkinson's disease. All of them were treated with L-DOPA preparations. The disease duration ranged from one to 12 years (average: 6.3 years). The severity of motor-related symptoms was assessed as per UDPRS part III and amounted to 19.25 points on average. Patients with a genetic variant of Parkinson's disease, as well as its classic type were selected for the tests.

A comparative group comprised 5 persons without diagnosed PD. 2 men and 3 women, aged 38 on average were tested within this group. 
The recording scenario was divided into several parts. The first part contained two texts of various emotional undertone, read out by the tested person. Yet another segment involved recording the vowel "a" with prolonged phonation, uttered by a patient for at least 5 seconds and recording spoken text involving repeated pronunciation of the "pa" syllable. The last part of the recordings involved the patient uttering individual words and sentences according to an assumed scenario. The results of the thus conducted studies were series of statements by each patient, significantly different linguistically, which provides valuable material for the comparative analysis of the voice. A total of 7 acoustic signals per patient, with an average length of ca. 75 seconds were recorded. The texts were usually recorded around noon, after the morning LDOPA dose was taken. The tests were conducted in a soundproof room with an average noise level of ca. $30 \mathrm{~dB}$, using Matlab software and a Shure SM57 dynamic microphone with a built-in USB interface, with a computer equipped with a sound car. Such a configuration, regardless of the used computer, enables recording a pure, natural sound without any interference coming from the computer system. All of the recordings were recorder with a sampling rate of $44.1 \mathrm{kSa} / \mathrm{s}$ and a 16-bit resolution.

\section{VOICE PROCESSING TECHNIQUES}

Acoustic voice analysis in PD patients can be a valuable and objective tool supporting the diagnosing diseases of neurodegenerative nature. This chapter presents voice processing techniques in evaluating patients with Parkinson's disease. Using time analysis, frequency analysis and time-frequency analysis, the authors attempted acoustic voice analysis in that group of patients. The review was preceded by a description of the speech signal development process.

The analysis involved 5-second long recordings of the vowel "a" and syllable "pa", as well as a text with varying emotional undertone. The analysis was conducted using Maltab and Praat software [12, 13]..

\subsection{Speech signal development process}

To fully understand the formation process of sounds and converting them into speech, it is required to have the basic knowledge of anatomy and physiology of the vocal tract, including the larynx. This vocal system contains mainly the lungs, bronchi, trachea, larynx, tongue, palate, teeth, lips, jaw and cheeks. The lungs can be deemed as a power source for the other organs of the vocal system. The air pressure generated in the human lungs determines the volume of emitted sound. The place within the human organisms where acoustic vibrations are created (generated) is the larynx. Vibrating vocal folds, often mistakenly called vocal cords are the sound source and determine its pitch (fundamental frequency) and timbre (higher harmonics content). The process of glottal ligament closing and opening and is responsible for this. The number of closing and opening cycles per second, which determines the pitch, depends on their thickness, length and tension (and these depend on the sex and age) 14, 15]. Fundamental frequency changes when speaking as a result of natural intonation, and in the case of a male voice averages $100-130 \mathrm{~Hz}$, while for a female voice, it averages $200-260$ $\mathrm{Hz}$ [16]. An air flux forced through the glottis is modified according to the articulation tact in the vocal tract, the parameters of which depend on the position and shape of the mouth, tongue, cheeks and teeth, and significantly affect the resultant timbre.

\subsection{Method used for acoustic voice analysis}

\subsubsection{Time analysis}

The time analysis focused on studying two issues. The first one concerns speech volume measurements, whereas the second one concerns speech rate.

Speech signal volume is one of the basic features, which is possible to be subjectively assessed by a human. In general, the literature identifies the term volume with signal power or its intensity. Volume is affected by the used microphone and preamplifier gain. Due to the fact that all recordings were completed using the same equipment, it is possible to objectively compare the speech volume of the studied persons. The experiments involved studying the volume of the "a" sound uttered by a group of people with PD and the control group. The calculations utilized the formulas contained in [12]. The outcome was the volume waveform expressed in decibels, as shown in Fig. 1. 


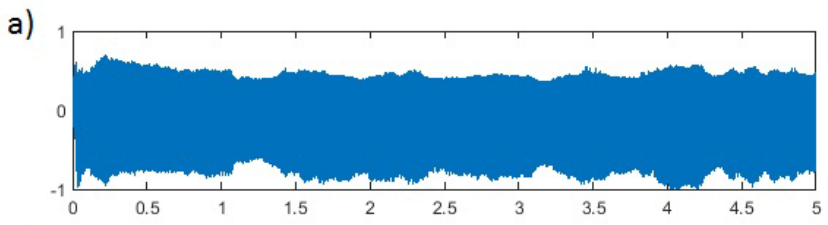

b)
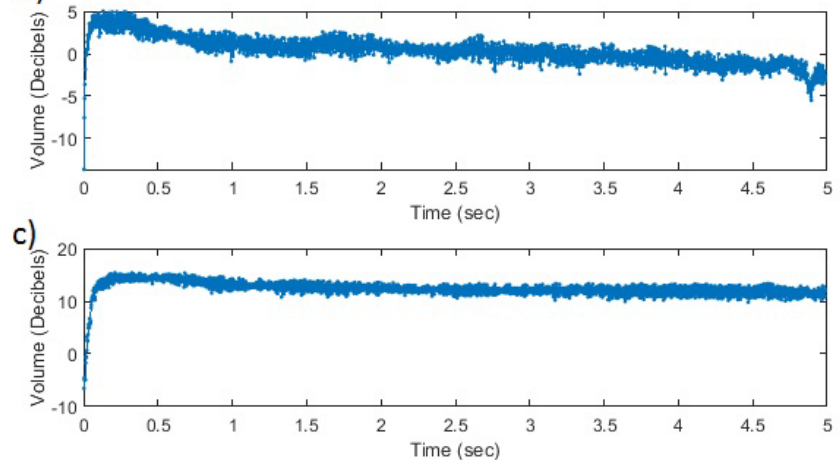

Figure 1. An example time waveform of the "a" sound with prolonged phonation ( 5 seconds) (a) and a volume waveform of a recording in $\mathrm{dB}$ in people with $\mathrm{PD}$ (b) and the control group (c).

The obtained waveform clearly shows the difference between the volume of a sound spoken by sick persons and the ones from the control group. In general, the speech of people affected by Parkinson's disease is characterized by mutation. The so-called speech volume reduction occurs, which is confirmed by the studies conducted by the authors. Most likely this is caused by weakening of the larynx and lung muscles, which are responsible for the speech signal formation process. At the same time, please note the volume level changing over time. The obtained waveforms clearly indicate that people with diagnosed PD, colloquially speaking, tire faster, which results in the volume of the spoken text decreasing over time. Differences in the volume level are quite significant.

Due to the same linguistic material, in the case of analysing the signal rate, the research involved studying the duration of a utterance of "sad" and "joyful" nature, the average number of "pa" syllable uttered within a 5-second period, as well as average time intervals between syllables. The parameters are defined below and the results shown in table 1:

- $\quad c_{1}$ - duration of a sad statement,

- $\quad c_{2}$ - duration of a joyful statement,

- $\quad c_{3}$ - number of uttered "pa" syllables during a 5-second speech fragment,

- $\quad c_{4}-$ duration of intervals between "pa" syllables.

Table 1. Exemplary time analysis results in PD patients.

\begin{tabular}{|l|l|l|l|l|l|l|l|l|}
\hline & range $\mathbf{c}_{1}$ & average $\mathbf{c}_{1}$ & range $\mathbf{c}_{2}$ & average $\mathbf{c}_{2}$ & range $\mathbf{c}_{3}$ & average c3 & range $\mathbf{c}_{4}$ & average $\mathbf{c}_{4}$ \\
\hline $\begin{array}{l}\text { Tested } \\
\text { group }\end{array}$ & $36-55$ & 43 & $36-55$ & 40.66 & $15-26$ & 20.33 & $0.08-0.14$ & 0.108 \\
\hline $\begin{array}{l}\text { Control } \\
\text { group }\end{array}$ & $31-40$ & 35.7 & $31-37$ & 33.7 & $20-29$ & 23.2 & $0.05-0.12$ & 0.85 \\
\hline
\end{tabular}

Such measurements enable evaluating the rate of speech in the form of the number of words spoken per minute, due to the analysis of a text of the same linguistic content or conducting such an analysis using a method of counting the 
number of spoken "pa" syllables relative to a 5-second segment of speech. The obtained results indicate a general trend of an extending speech duration in people with PD. Both the average speech time is longer, as well as the number of "pa" syllables per an analysed 5-second speech segment are lower. In the case of pilot studies, it was particularly evident in patients with advanced Parkinson's disease, falling within the upper part of the UPDRS. As a result, the rate of speech in people with PD is lower than in people from the control group. According to the studies, the average speaking rate is approximately 2.5 word per second, which amounts to 125 to 150 words per minute, whereas it should be emphasized that it may vary depending on the language, place of residence and many other factors [17]. In the case of the analysed texts, we had to deal with the same number of words. For a text with an optimistic undertone, the number of words was 86, while in the case of a sad text, this number was 90. Therefore, in general, Bradylalia, which is slow speech, can be determined in the case of people with diagnosed Parkinson's disease. A change in the tension of laryngeal muscles impacts sound intensity, and the duration of ligament vibrations affects the decision in terms of sound duration [3].

An interesting aspect of the studies, which was not analysed widely by the authors, however, which draws attention to the issue concerning people with PD is the stability of time intervals between successively uttered "pa" syllables. An example time waveform with marked time intervals between subsequent syllables is shown in Fig. 2. Preliminary pilot studies enable concluding the lack of stability in the intervals between subsequent syllables and, in general, a lower rate of uttering syllables within a specific time unit.

Time parameters are the parameters primarily utilized to assess prosodic vocal properties. In the case of acoustic speech signal analysis these are frequently also parameters, which are possible to be estimated by means of hearing and are an important element in evaluating a PD patient. The application of ready parameter extracting procedures using analysis of the time domain will facilitate patient's history taking and may possibly support the potential development or regression of a disease.

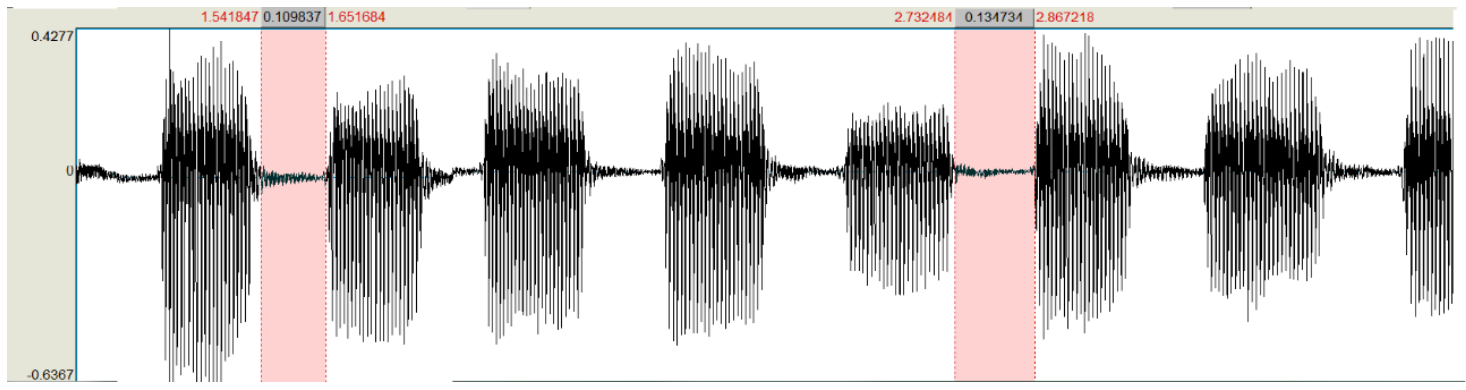

Figure 2. An example time waveform with marked intervals between subsequent "pa" syllables in a patient diagnosed with Parkinson's disease.

\subsubsection{Frequency analysis}

The frequency analysis involved evaluating the changes in the fundamental frequency of the laryngeal tone, depending on the nature of the text uttered by an examined person. The fundamental frequency of a sound is determined in the literature using numerous methods [19-21]. Algorithms for detecting $F_{0}$ can be divided into methods operating within the time domain, frequency domain and both domains simultaneously. The common feature of the algorithms is detecting fundamental frequency only in the so-called voiced portions of the speech signal, due to the fact that non-voiced signals are of noise nature. The analysed signal frames shall be selected in terms of their voicing for this purpose. The standard is to use the autocorrelation function for this purpose, determining a certain threshold above which the frames are deemed voiced $[22,23]$. Furthermore, the autocorrelation function was used by the authors to determine the fundamental frequency, because the determination method utilizing this function is, according to the researchers throughout the world, encumbered with the lowest error [24].

If a frame is deemed voiced, the value of its corresponding $F_{a c}$ fundamental frequency is determined according to the relationship:

$$
F_{a c}=\frac{f_{p}}{k_{\max }}=\frac{1}{k_{\max } \cdot T_{p}}
$$


where $k_{\max }$ is the index of the second maximum of the autocorrelation function $r(k)$, and $f_{p}$ - the signal sampling frequency.

Fundamental frequency stability was assessed in the course of a long-term analysis, using texts of both joyful, as well as sad nature. A short-term analysis using the "a" sound with prolonged phonation was also conducted. In each of the analysed cases, in order to perform a digital analysis of a signal, segmentation is required. A speech signal analysed as a whole cannot be deemed a stationary signal, since its properties change significantly over time. However, if the signal is to be analysed against short time intervals (in the order of several milliseconds), during which the properties change only slightly, it can be treated as a quasi-stationary signal. Each frame is analysed individually, and the overall analysis is always a resultant analysis of the individual speech signal frames.

Fundamental frequency was calculated for $20 \mathrm{~ms}$ long speech signal frames with $5 \mathrm{~ms}$ long overlays. An example graph presenting a changing fundamental frequency of the laryngeal tone for the short-term analysis regarding a healthy and sick person is shown in Fig. 3.
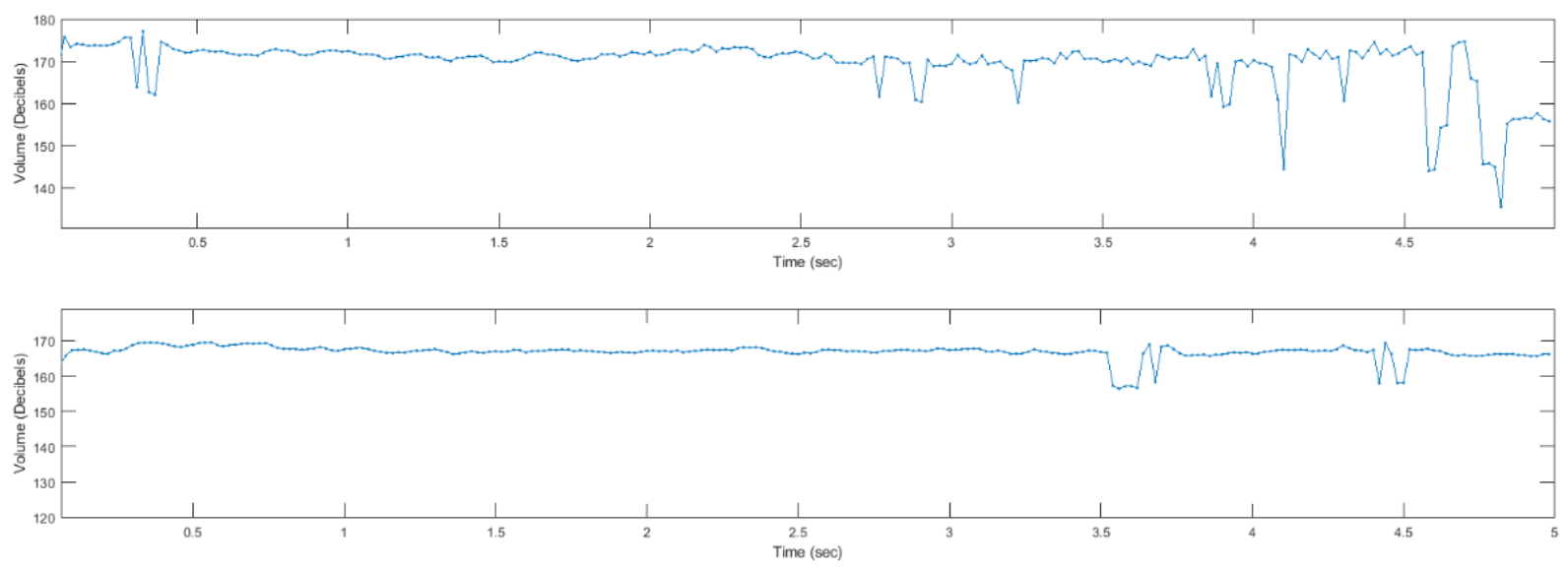

Figure 3. Example waveform of fundamental frequency variations during prolonged phonation of the "a" sound (short-term analysis) in a sick (top) and healthy (bottom) person.

The waveform of the fundamental frequency variations during prolonged phonation of the "a" sound indicates that the patients in the studied group exhibited higher instability of the fundamental frequency. It demonstrates the irregular work of the vocal folds, and more precisely, irregular frequency of their opening and closing. As a result, impaired laryngeal operation is the case for people with Parkinson's disease [21]. It is particularly visible in the second half of the analysed time period. People with PD have difficulty in maintaining the utterance of a sound with the same pitch.

When looking for speech signal features, which correlate with the issue of early PD diagnostics, attention should be primarily paid to the fundamental frequency changes and the correlated statistical parameters, and bit the very value of the fundamental frequency, which is rather an indicator of the studied person's identity.

The fundamental frequency was also extracted in the case of uttering texts of joyful and sad nature. The long-term analysis involved experiments aimed at evaluating speech monotony. All of this because it is widely believed that people with Parkinson's disease are characterized by speech with a weaker emotional tinge. Table 2 shows the range of fundamental frequency changes when texts of various emotional undertone are uttered by a healthy woman, and a woman with diagnosed PD (both of similar age). The analysis time was about 30 seconds.

Fig. 4 shows also the changes of fundamental frequency when texts of sad undertone (duration: 15 seconds) are uttered by a healthy person and a person diagnosed with Parkinson's disease. 
Table 1. The range of fundamental frequency changes when texts of various emotional undertone are uttered by a healthy woman, and a woman with diagnosed PD (both of similar age)

\begin{tabular}{|l|c|c|c|c|}
\hline \multirow{2}{*}{ Parameter } & \multicolumn{3}{|c|}{ Text of sad undertone } & \multicolumn{2}{c|}{ Text of optimistic undertone } \\
\cline { 2 - 5 } & healthy & sick & healthy & sick \\
\hline F 0_average $_{\text {F } \_ \text {std }}$ & 218 & 202 & 215 & 170 \\
\hline
\end{tabular}
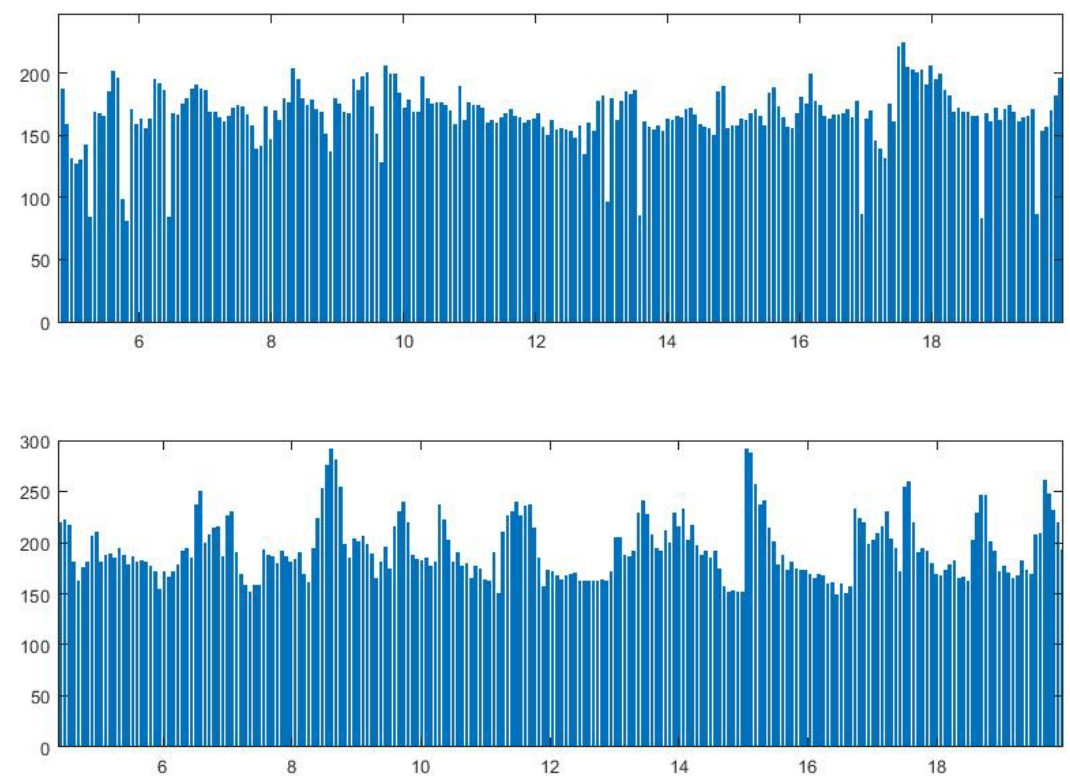

Figure 4. Graph of laryngeal tone fundamental frequency changes for a text of sad nature (long-term analysis) uttered by a sick person (top) and a healthy person (bottom).

Based on the conducted experiments, it can be easily concluded that the fundamental frequency changes over a broader range in a healthy person. This is evidenced both by the range of fundamental frequency changes, as well as the standard deviation calculated for this parameter. As a result, the speech of people with PD is characterized by higher monotony and lack of modulation [21]. Although the read-out text was marked emotionally, people with diagnosed PD did not explicitly emphasize that fact during the recordings, which could be felt directly and subjectively in the course of the study.

Another study within the frequency analysis was the evaluation of speech voicing in people with Parkinson's disease. The voicing of the frames was assessed for this purpose. The aforementioned autocorrelation function was used as the selection criterion. For this purpose, the authors formulated the so-called voicing coefficient, which is defined as follows

$$
\text { voicing coefficient }=\frac{\text { number of voiced speech signal frames }}{\text { number of all speech signal frames }}
$$

The variability graph for this parameter, depending on the nature of the spoken text, is shown below. The values on the left are for the group with diagnosed PD. The values on the right are for the control group. 


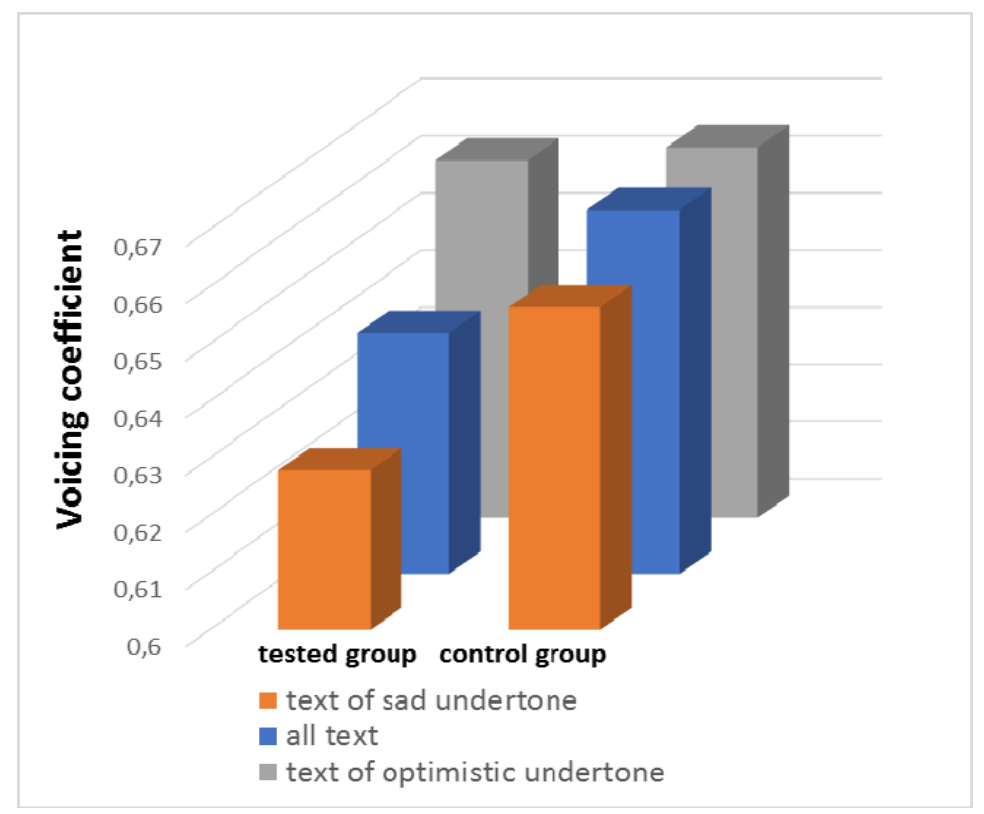

Figure 5. Voicing coefficient variability graph during the long-term analysis of statements of varying emotional undertone.

The results of the conducted experiments indicate lower values of the voicing coefficients in people with diagnosed Parkinson's disease. Due to the fact that the study involved the same linguistic text, it can be speculated that in this case, the difference in experiment results is caused primarily by weaker operation of the vocal folds, as well as by the stiffness of the oral cavity, pharynx and larynx muscles in those patients. Furthermore, it can be caused by the issue of generating voiced vowels like "b" and inaccurate articulation in patients with PD [3].

The frequency analysis also involved comparing the amplitude spectra for individual words spoken by the studied persons. Examples of amplitude spectra in a decibel scale are shown in the figure below.
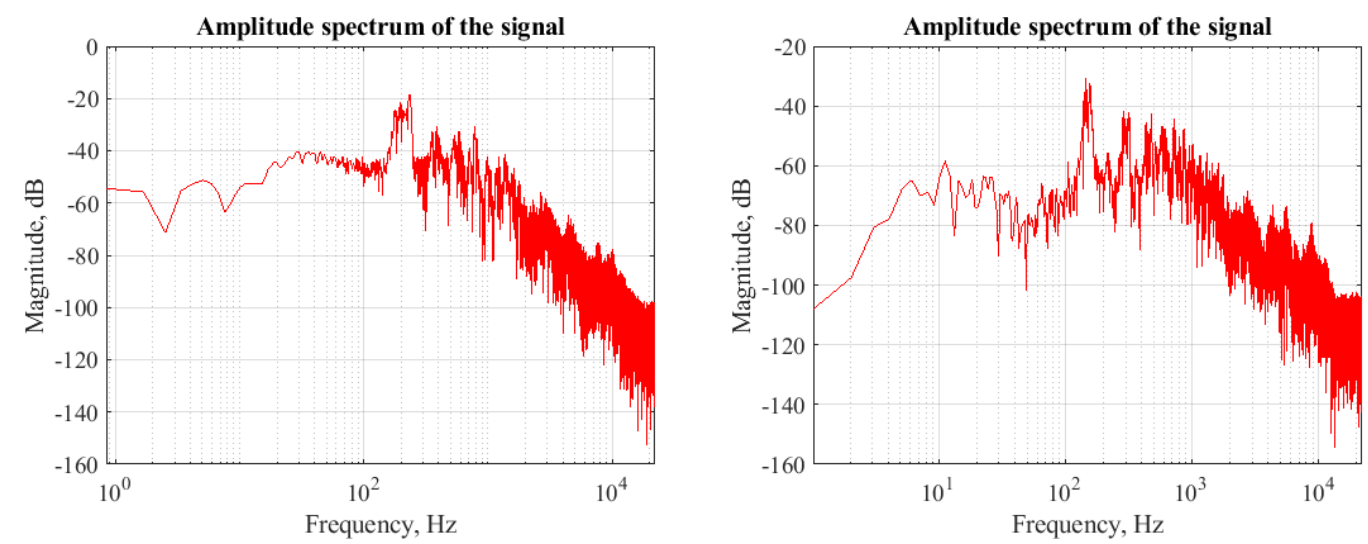

Figure 6. Amplitude spectrum graph when uttering the word "aeroplan" (Eng. aeroplane). Healthy person on the left, sick person on the right.

Within the speech signal spectrum analysis (the word "aeroplan"), we can observe reduced vocal range, especially in terms of high frequencies. Amplitude for a person with diagnosed Parkinson's disease is lower.

\subsubsection{Time-frequency analysis}

The short-time Fourier transform (STFT) was used within the time-frequency analysis. This method involved successive division into segments of a signal section intended for analysing, each of which is independently subject to spectral 
analysis. Just like in the traditional case, in order to remove signal changes (cuts) at range extremes, various time windows are applied relative to the aforementioned segments. Shifting a time window along the signal determines its spectral content inside the time interval, the length of which is defined by the window width [22].

The acoustic waveform analysis based on spectrograms is an analysis of the long-term type. It is usually applied for recorded words and sentences, although it is also possible to use it for individual sounds. The research included analysing the word "aeroplan" (Eng. aeroplane), and the results' examples are shown in Fig. 7.
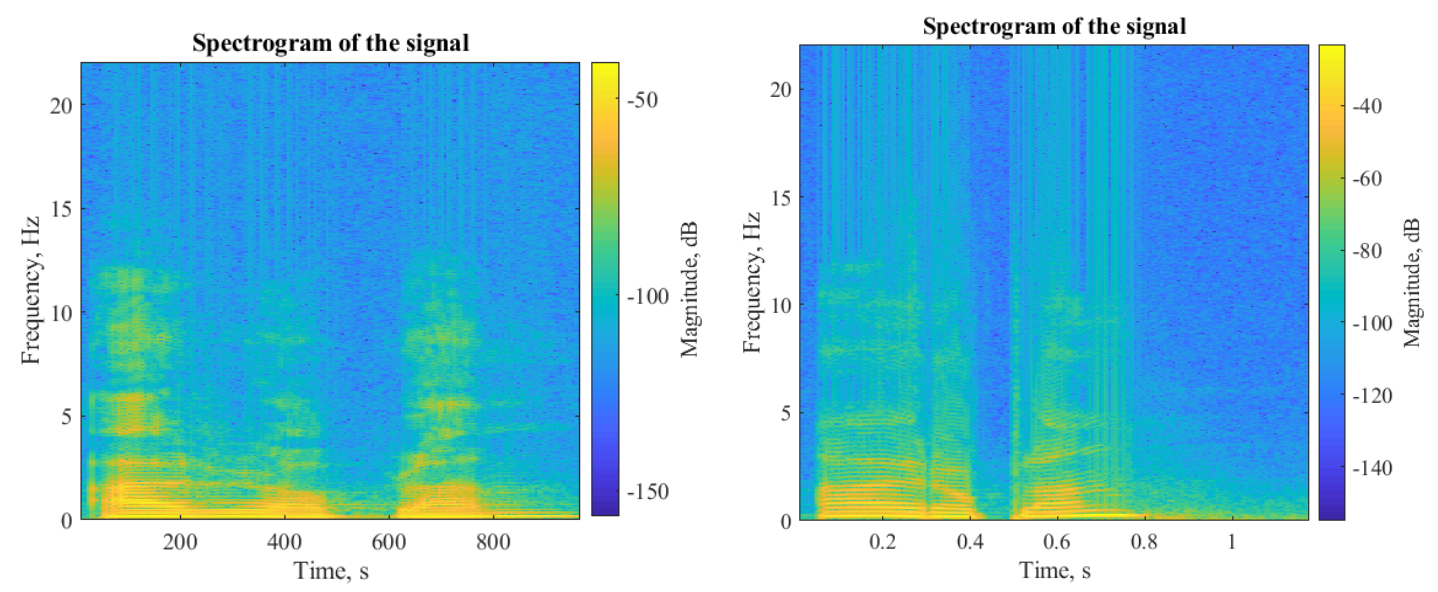

Figure 7. Spectrogram for the word "aeroplan". Healthy person on the left, sick person on the right.

The spectrogram analysis indicates that Parkinson's disease impacts the entire frequency range increasing their occurrence intensity. The spectrogram contrast degree (or otherwise - its clarity) is a measure of speech signal disturbances. The differences in the spectrograms most likely result from the varying proper closure of the vocal folds. Immediately after the vocal folds close, the harmonic structure is the richest, and the amplitude of all frequency components the greatest. As a result, the operation of the vocal folds is all the more efficient, the better the spectrogram contrast [24].

\section{CONCLUSIONS}

The presented research paper discusses the application of selected voice processing methods in terms of their potential use for objective support of diagnosing people with Parkinson's disease. This was the objective of the pilot studies conducted at the Department of Neurology at the Medical University of Warsaw, which included recording selected multimodal data, including voice $[8,9]$

The experiments included time, frequency and time-frequency analyses using selected speech signal processing techniques. The studies focused on both short-term, as well as long-term analysis. It should be noted that the patients participating in the study were characterized by varying disease severity and were under the influence of drugs during the recordings, which resulted in decreased disorders characteristic of the disease. As a result, the interpretation of voice analysis results was hindered.

The acoustic structure of speech in a group of PD patients significantly differed at each analysis stage. The most subjective differences are noticeable within the time domain. A change in the speaking rate, monotony, poor emotional undertone of the spoken text and muting were one of the basic features identified within the conducted pilot studies.

Acoustic analysis reveals a number of physical phenomena distinguishing the speech signal, which were unrecognizable to hearing only. This is where frequency and time-frequency analyses come in handy. A decreased voicing coefficient, as well as significant changes in the frequency structure of the speech signal were, among others, identified in this domain. Furthermore, abnormal operation of the vocal folds, which is possible to detect only by such analyses can be observed. 
To sum up, both the time analysis, as well as the frequency and time-frequency analyses can be a useful tool confirming changes in the voice of people diagnosed with Parkinson's disease. Further studies involving larger groups are required in order to confirm the obtained results and the structure of a target diagnostic system.

\section{ACKNOWLEDGEMENTS}

Project co-financed from the funds of the Polish Ministry of National Defense for the implementation of basic research within the research grant No. GBMON/B9/13-996/2018 "Basic research in the field of sensor technology using innovative data processing methods".

\section{REFERENCES}

[1] Gaweł, M., Potulska-Chromik A., "Choroby neurodegeneracyjne: choroba Alzheimera i Parkinsona (Neurodegenerative diseases: Alzheimer and Parkinson's diseases)", Postępy Nauk Medycznych XXVIII(7), 468-476 (2015).

[2] Zajkowska, A., “Choroba Parkinsona (Parkinson's disease)”, Neurologia po Dyplomie, June 2017, $<$ https://podyplomie.pl/neurologia/29021, choroba-parkinsona> (11 September 2019).

[3] Pawlukowska, W., Honczarenko, K., Gołab-Janowska, M., "Charakter zaburzeń mowy w chorobie Parkinsona (Speech impairment nature in Parkinson's disease)”, Neurologia i Neurochirurgia Polska 47(3), 263-269 (2013).

[4] Factor, S. A., [Parkinson's Disease: Diagnosis \& Clinical Management], Second Edition, (2002).

[5] Parkinson, J., "An Essay on the Shaking Palsy. 1817”, The Journal of Neuropsychiatry 4(2), 223-236 (2002).

[6] Hughes, AJ., Daniel, SE, Kilford, L., Lees, AJ., “Accuracy of clinical diagnosis of idiopathic Parkinson's disease: a clinico-pathological study of 100 cases", J Neurol Neurosurg Psychiatry 55 (3), 181-184 (1992).

[7] Gorzkowska, A., Jasińska-Myga, B, Opala, G., "Kryteria rozpoznawania, różnicowanie, obraz kliniczny zaburzeń ruchowych oraz powikłania ruchowe późnego okresu choroby (Diagnostic criteria, differentiation, motor disorder clinical picture and motor complications of later disease stage). Sławek, W., Friedman, J., Bogucki, A., Opala, G. (red.), „Choroba Parkinsona i inne zaburzenia ruchowe” (Parkinson’s Disease and other motor disorders). Via Medica, 2, 118-125 (2011).

[8] Chmielińska, J., Białek, K., Potulska-Chromik, A., Jakubowski, J., Majda-Zdancewicz, E., Nojszewska, M., Kostera-Pruszczyk, A., Dobrowolski, A., "Stanowisko do rejestracji multimodalnych danych na potrzeby obiektywnej oceny choroby Parkinsona (Multimodal data acquisition set for objective assessment of Parkinson's disease)", X Konferencja Naukowa Urządzenia i Systemy Radioelektroniczne (10th Scientific Conference - Radioelectronic Equipment and Systems) UiSR 2019, conference materials (2019).

[9] Białek, K., Jakubowski, J., Potulska-Chromik, A., Chmielińska, J., Majda-Zdancewicz, E., Nojszewska, M., Kostera-Pruszczyk, A., Dobrowolski, A., "Wybrane zagadnienia wstępnego przetwarzania danych obrazowych w badaniu osób z chorobą Parkinsona (Selected problems of image data preprocessing used to perform examination in Parkinson's disease)", X Konferencja Naukowa Urządzenia i Systemy Radioelektroniczne (10th Scientific Conference - Radioelectronic Equipment and Systems) UiSR 2019, conference materials (2019).

[10] Obeso, J. A. (ed.), “The Unified Parkinson's Disease Rating Scale (UPDRS): Status and recommendations”, Movement Disorders 18(7), 738-750 (2003).

[11] Morgan, J. C., Mehta, S. H., Sethi, K. D., “Biomarkery w chorobie Parkinsona (Biomarkers in Parkinson's disease)", Neurologia po Dyplomie 6(4), 28-37 (2011). 
[12] Jyh-Shing, R. Jang, "Audio $\quad$ Signal Processing and Recognition," $<$ http://mirlab.org/jang/books/audioSignalProcessing/> (25 September 2019).

[13]Pascal van Lieshout, "Praat Short Tutorial", University of Toronto, 7 October 2003. https://web.stanford.edu/dept/linguistics/corpora/material/PRAAT_workshop_manual_v421.pdf (11 December 2019).

[14] Tadeusiewicz, R., [Sygnał mowy (Speech signal)], Wydawnictwa. Komunikacji i Łączności, Warsaw, (1988).

[15] Otrębowski, A., [Narząd głosu i jego znaczenie w komunikacji społecznej (Vocal organ and its significance in social communication)], Wydawnictwo Naukowe Uniwersytetu Medycznego (2008).

[16] Pawłowski, Z., [Foniatryczna diagnostyka wykonawstwa emisji głosu śpiewaczego i mówionego (Phoniatric diagnostics regarding sung and spoken voice emission quality)], Impuls (2005).

[17]Zyss, T., Zięba, A., “Tempo mówienia - kilka uwag z psychiatrycznego punktu widzenia (Speaking rate several remarks from a psychiatric perspective)", Neurolingwistyka Praktyczna 1, 15-26 (2015).

[18]Krysiak, A., "Zaburzenia języka, mowy i komunikacji w chorobie Parkinsona (Language, speech and communication disorders in Parkinson's disease)", Neuropsychiatra i Neuropsychologia 6 (1), 36-42 2011.

[19] Yegnanarayana B.; Sri Rama Murty K., "Event-Based Instantaneous Fundamental Frequency Estimation From Speech Signals", IEEE Transactions on Audio, Speech, and Language Processing 17(4), 614 - 624 (2009).

[20] Muhammad, G., "Automatic voice pathology detection and classification using vocal tract area irregularity", Biocybernetics and Biomedical Engineering 36(2), 309-317 2016.

[21] Harel, B, Cannizzaro, M., Snyder PJ, "Variability in fundamental frequency during speech in prodromal and incipent Parkinon;s disease", Brain and Cognition 56 (1), 24-29 (2004).

[22] Smith, S. W.: [Cyfrowe przetwarzanie sygnałów: Praktyczny poradnik dla inżynierów i naukowców (Digital signal processing. Practical guide for engineers and scientists)], BTC (2007).

[23] Majda, E., Dobrowolski, A. P., "Modelling and optimization of the feature generator for speaker recognition systems", Przegląd Elektrotechniczny 88 (12A), 131-136 (2012).

[24] Mekyska, J., et al., "Robust and complex approach of pathological speech signal analysis", Neurocomputing 167(1), 94-111 (2015). 